\title{
Estrutura curricular dos cursos de graduação em Odontologia nos países constituintes do Mercosul
}

\author{
Karine Angar*; Adair Luiz Stefanello Busato**; Rubem Beraldo dos Santos**; Ivana Ardenghi \\ Vargas**; Ricardo Prates Macedo**; Pedro Antônio González Hernandez** $^{* *}$ \\ * Professora Doutora, Curso de Odontologia, Universidade \\ da Serra Gaúcha \\ ** Professor(a) Doutor(a), Curso de Odontologia, \\ Universidade Luterana do Brasil, Campus Canoas \\ Recebido: 11/09/2020. Aprovado: 23/09/2021.
}

\begin{abstract}
RESUMO
Este estudo objetivou analisar a organização curricular dos cursos de graduação em Odontologia nos países membros do Mercado Comum do Sul (Mercosul), tendo como base a estrutura de agrupamento de conteúdos essenciais estabelecida pela Resolução CNE/CES n 3, de 19 de fevereiro de 2002 e ratificada pela Resolução ${ }^{\circ} 3$, de 21 de junho de 2021. A seleção de cursos foi realizada a partir de dados existentes em órgãos governamentais dos diferentes países identificados como universo de estudo, assim como na base de dados Universia. A amostra foi constituída pelos currículos desses cursos obtidos nos sites de suas respectivas instituições, sendo 141 cursos incluídos no Brasil, 8 na Argentina, 2 no Paraguai e 2 no Uruguai. As cargas horárias das disciplinas constituintes das matrizes curriculares destes cursos foram somadas, de acordo com o Artigo $6^{\circ}$ das Diretrizes Curriculares Nacionais (DCN) Brasileiras, sendo este subdividido em Ciências Biológicas e da Saúde, Ciências Humanas e Sociais e Ciências Odontológicas. Os dados foram analisados por meio de estatística descritiva. A análise dos resultados permite concluir que há similaridade, atual, de estrutura curricular, com algumas características a serem salientadas como a maior carga-horária exigida no Paraguai e a menor, no Brasil. Outros estudos relacionados com a temática, utilizando outras formas de coleta de dados e percursos metodológicos, são imprescindíveis para que se possa avaliar possibilidades de aproximação e trânsito livre de egressos, visando um perfil profissiográfico regional, que favoreça a possibilidade de, no futuro, estabelecer uma estratégia de "formação para a integração" nos Estados Partes do Mercosul.
\end{abstract}

Descritores: Currículo. Educação em Odontologia. Ensino Superior. Estudos de Avaliação. Mercosul.

\section{INTRODUÇÃO}

A estruturação curricular dos cursos de Odontologia, definida na Resolução CNE/CES n ${ }^{\circ}$ $3 / 2002$, de 19 de fevereiro de 2002, ratificada pela Resolução n 3, de 21 de junho de 2021, sugere que os conteúdos devem estar relacionados com todo o processo de saúde-doença do cidadão, da família e da comunidade e, formalmente, são divididos em três grupos: Ciências Biológicas e da Saúde; Ciências Humanas e Sociais e Ciências Odontológicas $^{1,2}$.

$\mathrm{Na}$ perspectiva nacional, embora com grandes dificuldades no processo de ruptura em relação ao currículo mínimo tradicional, os cursos de graduação, nem sempre uniformemente, avançam na reestruturação dos seus projetos 
pedagógicos. Entretanto, é evidente a incipiência na discussão sobre uma estruturação curricular que reflita o perfil profissiográfico do egresso, capacitado para a atuação profissional regional, nos países membros do Mercado Comum do Sul (Mercosul).

Instituído em 26 de março de 1991 pelo Tratado de Assunção, Mercosul é um projeto de integração concebido e implementado pela Argentina, Brasil, Paraguai e Uruguai, envolvendo dimensões econômicas, políticas e sociais tratadas por diversos órgãos e instâncias, que geralmente funcionam na forma colegiada, com representação dos Estados Partes. No aspecto econômico, o Mercosul assume, hoje, o caráter de União Aduaneira, ainda que seu fim seja constituir-se em Mercado Comum, conforme os objetivos estabelecidos no Tratado de Assunção ${ }^{3}$.

Durante a $53^{\text {a }}$ Cúpula dos Chefes de Estados do Mercosul e Estados Associados, realizada em 18 de dezembro de 2018, foi assinado um acordo que pretende simplificar o processo de revalidação dos diplomas de graduação dos países membros e associados. Embora o teor integral do referido acordo ainda não seja de domínio público, a imprensa noticiou que a aplicação da validação será feita de forma gradual entre os países e o princípio de reciprocidade será adotado e objetivará processualmente à análise estritamente documental, sem necessidades de outros critérios. Destaca-se, na notícia, que os cursos incluídos no acordo serão apenas aqueles reconhecidos no Sistema ARCU-SUR ${ }^{4}$, entre os quais se encontram os cursos de graduação em Odontologia.

Considerando uma futura integração que vise o trânsito livre de profissionais, este estudo objetiva analisar a organização curricular dos cursos de graduação em Odontologia nos países constituintes do Mercosul.

\section{METODOLOGIA}

O presente estudo é classificado como uma pesquisa descritiva e documental ${ }^{5}$, tendo sido aprovado pelo Comitê de Ética em Pesquisa em Seres Humanos da Universidade Luterana do Brasil, parecer $n^{\circ}$ 2.344.196.

A operacionalização da pesquisa foi realizada em quatro etapas e os dados foram coletados no período de outubro de 2017 a outubro de 2018: 1) levantamento dos dados das instituições de ensino superior do Brasil por meio do site e-MEC (http://emec.mec.gov.br/) e dos demais países do Mercosul (Argentina, Paraguai e Uruguai) por meio do site Universia (http://www.universia.net/); 2) realização do cálculo amostral, com intervalo de confiança de 95\%, para definir o número de cursos de graduação de Odontologia, por país, que deveriam ser estudados; 3) identificação das matrizes curriculares vigentes de cada curso de Odontologia cadastrado nos sites referidos anteriormente, conforme cálculo amostral; 4) análise quantitativa estatística das cargas horárias $(\mathrm{CH})$ totais e estratificadas de acordo com as categorias das Diretrizes Curriculares Nacionais (DCN) estabelecidas no Brasil.

O cálculo amostral (com confiança de $95 \%$ e um erro máximo de estimação de $5 \%$ ) definiu a necessidade de analisar 189 currículos, sendo 178 no Brasil, 8 na Argentina, 2 no Paraguai e 2 no Uruguai.

As matrizes curriculares foram analisadas por uma observadora treinada. As cargas horárias totais foram somadas, assim como as $\mathrm{CH}$ parciais, definidas em consonância com os agrupamentos de conteúdos essenciais estabelecidos pelas DCN para os cursos de Odontologia por meio da Resolução $\mathrm{CNE} / \mathrm{CES} \mathrm{n}{ }^{\circ} 3,19$ de fevereiro de 2002, artigo $6^{\circ 1}$. Dessa forma, foram considerados os agrupamentos: Ciências Biológicas e da Saúde; Ciências Humanas e Sociais e Ciências Odontológicas, este último, dividido em Propedêutica Clínica; Clínica Odontológica e Odontologia Pediátrica. No caso de existirem 
disciplinas que não correspondessem a essa classificação, as respectivas cargas horárias foram agrupadas numa sexta coluna denominada como não pertencente a nenhum eixo das DCN (NPNE). As somas das cargas horárias estruturadas nas seis colunas foram agrupadas numa sétima coluna denominada como carga horária total.

Os dados foram analisados por meio de estatística descritiva e testes não-paramétrico de Friedman e de Mann-Whitney, apresentados por meio de tabelas. O software utilizado para a análise estatística foi o Statistical Package for the Social Sciences (IBM, Armonk, NY, EUA) versão 22.0.

\section{RESULTADOS}

Considerando eventuais inconsistências para a obtenção e/ou análise da informação, como dados incompletos nos sites (matrizes curriculares com apenas o nome das disciplinas - sem $\mathrm{CH}$ ou somente o número de créditos, sem especificar a $\mathrm{CH}$ de cada um, ou matrizes curriculares idênticas em IES localizadas em mais de uma cidade e/ou estado, entre outros) optou-se por excluir da amostra 37 currículos, todos oriundos de Cursos de Odontologia no Brasil, resultando em 20\% de perda da amostra original. Em consequência dessa perda, a análise neste estudo contemplou 153 currículos e, desses, 141 brasileiros, 8 argentinos, 2 paraguaios e 2 uruguaios.

A análise dos resultados e comparativos decorrentes considerou o valor da mediana, por se constituir em uma medida de tendência central mais robusta que a média. Observa-se que para concluir o Curso de Odontologia o Paraguai é o país que exige maior $\mathrm{CH}$ e o Brasil a menor (tabela $1)$.

Ao serem estratificados, por países, os dados de $\mathrm{CH}$ conforme a estrutura estabelecida nas DCN brasileiras, se observa que a menor carga horária encontrada no Brasil está no eixo das Ciências Odontológicas, no subeixo Propedêutica Clínica, com 252,0 horas-aula. Já a maior carga horária encontra-se no mesmo eixo (Ciências Odontológicas), no subeixo Clínica Odontológica, com 2130,0 horas-aula (tabela 2).

Por meio dos resultados do teste nãoparamétrico de Friedman, para as cargas horárias nos três eixos, nas matrizes curriculares brasileiras, se verifica que existe diferença significativa para os valores comparados. A maior $\mathrm{CH}$ é disponibilizada para o eixo Ciências Odontológicas, com média de 2763,0 horas-aula e a menor $\mathrm{CH}$ é disponibilizada para o eixo Ciências Humanas e Sociais, com média de 534,8 horasaula ( $\mathrm{p}=0,000)$ (tabela 3$)$.

A análise entre a estrutura de $\mathrm{CH}$ nos cursos de Odontologia no Brasil comparativamente às estruturas de cargas horárias agrupadas dos restantes países membros do Mercosul mostrou os seguintes resultados: ao agrupar os dados, tendo como critérios (carga horária - Brasil / carga horária - outros países do Mercosul) e realizar a análise dos mesmos por meio do teste nãoparamétrico de Mann-Whitney verificou-se que a CH média disponibilizada nesses países para competências relacionadas às Ciências Biológicas e da Saúde é estatisticamente superior à praticada no Brasil (tabela 4).

Tabela 1. Carga horária total de Cursos de Odontologia nos países do Mercosul

\begin{tabular}{llcccccc}
\hline Variável & País & n & Mínimo & Máximo & Mediana & Média & Desvio Padrão \\
\hline \multirow{3}{*}{ Carga horária total } & Brasil & 141 & 2940,0 & 6090,0 & 4125,0 & 4223,3 & 540,0 \\
do curso & Argentina & 8 & 3898,0 & 7200,0 & 4646,0 & 4877,9 & 984,0 \\
& Uruguai & 2 & 4370,0 & 6265,6 & 5317,8 & 5317,8 & 1340,4 \\
& Paraguai & 2 & 6649,0 & 6649,6 & 6649,3 & 6649,3 & 0,4 \\
& Total & 153 & 2940,0 & 7200,0 & 4175,0 & 4303,6 & 659,0 \\
\hline
\end{tabular}


Tabela 2. Estruturação da carga horária de acordo com os grupos estabelecidos pelas DCN

\begin{tabular}{|c|c|c|c|c|c|c|}
\hline País & Áreas & Mínimo & Máximo & Mediana & Média & Desvio Padrão \\
\hline \multirow{8}{*}{$\begin{array}{l}\text { Brasil } \\
(n=141)\end{array}$} & Ciências Biológicas e da Saúde & 333 & 1344 & 680 & 680,9 & 150,8 \\
\hline & Ciências Humanas e Sociais & 80 & 1355 & 510 & 534,8 & 227,8 \\
\hline & Ciências Odontológicas & 2000 & 5190 & 2682 & 2763 & 517,9 \\
\hline & a) Propedêutica Clínica & 60 & 1365 & 252 & 273,7 & 137,5 \\
\hline & b) Clínica Odontológica & 1400 & 4980 & 2130 & 2185,6 & 511,7 \\
\hline & c) Odontologia Pediátrica & 120 & 520 & 304 & 303,7 & 98,8 \\
\hline & Outras (NPNE*) & 0 & 1134 & 220 & 244,6 & 186,1 \\
\hline & Carga horária total do Curso & 2940 & 6090 & 4125 & 4223,3 & 540 \\
\hline \multirow{8}{*}{$\begin{array}{l}\text { Argentina } \\
(n=8)\end{array}$} & Ciências Biológicas e da Saúde & 768 & 1170 & 848 & 917,4 & 152,2 \\
\hline & Ciências Humanas e Sociais & 273 & 765 & 456 & 480,6 & 149,3 \\
\hline & Ciências Odontológicas & 2280 & 5370 & 2937,5 & 3192 & 977,6 \\
\hline & a) Propedêutica Clínica & 80 & 1180 & 373 & 391,3 & 352,2 \\
\hline & b) Clínica Odontológica & 1600 & 2688 & 2250 & 2160,5 & 485,7 \\
\hline & c) Odontologia Pediátrica & 120 & 2520 & 301,5 & 640,3 & 788,1 \\
\hline & Outras (NPNE*) & 60 & 834 & 252,5 & 287,9 & 247,1 \\
\hline & Carga horária total do Curso & 3898 & 7200 & 4646 & 4877,9 & 984 \\
\hline \multirow{8}{*}{$\begin{array}{l}\text { Uruguai } \\
(\mathrm{n}=2)\end{array}$} & Ciências Biológicas e da Saúde & 720 & 937,3 & 828,7 & 828,6 & 153,6 \\
\hline & Ciências Humanas e Sociais & 399,8 & 1181 & 790,4 & 790,4 & 552,4 \\
\hline & Ciências Odontológicas & 2319 & 4409,6 & 3364,3 & 3364,3 & 1478,2 \\
\hline & a) Propedêutica Clínica & 305 & 576 & 440,5 & 440,5 & 191,6 \\
\hline & b) Clínica Odontológica & 1744 & 3225,6 & 2484,8 & 2484,8 & 1047,6 \\
\hline & c) Odontologia Pediátrica & 270 & 608 & 439 & 439 & 239 \\
\hline & Outras (NPNE*) & 150 & 384 & 267 & 267 & 165,5 \\
\hline & Carga horária total do Curso & 4270 & 6265,6 & 5317,8 & 5317,8 & 1340,4 \\
\hline \multirow{8}{*}{$\begin{array}{l}\text { Paraguai } \\
(n=2)\end{array}$} & Ciências Biológicas e da Saúde & 1056 & 1560 & 1308 & 1308 & 356,4 \\
\hline & Ciências Humanas e Sociais & 800 & 1160 & 980 & 980 & 254,6 \\
\hline & Ciências Odontológicas & 4409 & 5500 & 4954,5 & 4954,5 & 771,4 \\
\hline & a) Propedêutica Clínica & 400 & 576 & 488 & 488 & 124,5 \\
\hline & b) Clínica Odontológica & 3225 & 4580 & 3902,5 & 3902,5 & 958,1 \\
\hline & c) Odontologia Pediátrica & 520 & 608 & 564 & 564 & 62,2 \\
\hline & Outras (NPNE*) & 160 & 384 & 272 & 272 & 158,4 \\
\hline & Carga horária total do Curso & 6649 & 6649,6 & 6649,3 & 6649,3 & $\mathbf{0 , 4}$ \\
\hline
\end{tabular}

NPNE* Cargas horárias de disciplinas não identificadas em nenhum dos eixos de formação de acordo com as DCN (como Informática, Leitura e Interpretação de Texto, Educação Física, Disciplinas de Seminário, Trabalho de Conclusão de Curso, entre outras). 
Tabela 3. Estruturação da carga horária, em estratificação por eixos, de acordo com as DCN

\begin{tabular}{llcccc}
\hline Local & Área & Mediana & Média & Desvio Padrão & p \\
\hline \multirow{3}{*}{ Brasil (n=141) } & Ciências Biológicas e da Saúde & 680 & $680,9^{\mathrm{A}}$ & 150,8 & $0,000^{* *}$ \\
& Ciências Humanas e Sociais & 510 & $534,8^{\mathrm{B}}$ & 227,8 & \\
& Ciências Odontológicas & 2682 & $2763,0^{\mathrm{C}}$ & 517,9 & \\
\hline \multirow{3}{*}{ Argentina (n=8) } & Ciências Biológicas e da Saúde & 848 & $917,4^{\mathrm{A}}$ & 152,2 & $0,000^{* *}$ \\
& Ciências Humanas e Sociais & 456 & $480,6^{\mathrm{B}}$ & 149,3 & \\
& Ciências Odontológicas & 2937,5 & $3192,0^{\mathrm{C}}$ & 977,6 & \\
\hline \multirow{3}{*}{ Uruguai (n=2) } & Ciências Biológicas e da Saúde & 828,7 & 828,6 & 153,6 & Não se \\
& Ciências Humanas e Sociais & 790,4 & 790,4 & 552,4 & \\
& Ciências Odontológicas & 3364,3 & 3364,3 & 1478,2 & \\
\hline \multirow{3}{*}{ Paraguai (n=2) } & Ciências Biológicas e da Saúde & 1308 & 1308 & 356,4 & 0,135 \\
& Ciências Humanas e Sociais & 980 & 980 & 254,6 & \\
& Ciências Odontológicas & 4954,5 & 4954,5 & 771,4 & \\
\hline
\end{tabular}

Tabela 4. Carga horária relacionada às áreas, Curso de Odontologia do Brasil versus outros países membros do Mercosul

\begin{tabular}{llccccc}
\hline Área & País & n & Mediana & Média & Desvio Padrão & p \\
\hline \multirow{2}{*}{ Ciências Biológicas e da Saúde } & Brasil & 141 & 680 & 680,9 & 150,8 & $0,000^{* * *}$ \\
& Outros* & 12 & 892,6 & 967,7 & 234,2 & \\
\hline \multirow{2}{*}{ Ciências Humanas e Sociais } & Brasil & 141 & 510 & 534,8 & 227,8 & 0,578 \\
& Outros* & 12 & 479,5 & 615,5 & 301,3 & \\
\hline Ciências Odontológicas & Brasil & 141 & 2682 & 2763 & 517,9 & $0,026^{* *}$ \\
& Outros* & 12 & 4768,5 & 3514,5 & 1147,9 & \\
\hline Ciências Odontológicas - Propedêutica & Brasil & 141 & 252 & 273,7 & 137,5 & $0,026^{* *}$ \\
Clínica & Outros* & 12 & 408 & 415,6 & 291,8 & \\
\hline Ciências Odontológicas - Clínica & Brasil & 141 & 2130 & 2185,6 & 511,7 & 0,257 \\
Odontológica & Outros* & 12 & 2497,5 & 2504,9 & 880,2 & \\
\hline Ciências Odontológicas - Odontologia & Brasil & 141 & 304 & 303,7 & 98,8 & $0,031^{* *}$ \\
Pediátrica & Outros* & 12 & 417,5 & 594 & 637,9 & \\
\hline
\end{tabular}

Outros*: Argentina, Paraguai e Uruguai, ** Significativo para $\mathrm{p} \leq 0,05, * * *$ Significativo para $\mathrm{p} \leq 0,01$

\section{DISCUSSÃO}

Desde 2002, os países membros do Mercosul assinaram o "Acordo sobre residência para nacionais dos Estados Partes do Mercosul", que, entre outros preceitos, estabelece o direito do migrante residente a trabalhar no país de destino ${ }^{4}$. Este acordo, a priori, permitiria que egressos de cursos de graduação de um país membro poderiam exercer a profissão em um dos outros três países Estados Partes, mas, na prática, as regulações nacionais têm impedido, de certa forma, a facilidade desse intercâmbio. Até o presente momento, os títulos de graduação e pós-graduação devem ser devidamente validados pela legislação vigente nos Estados Partes ${ }^{6}$, embora, em 2009, com a promulgação da Decisão $n^{\circ} 17 / 08$ se aprovou o 
acordo sobre a criação e a implementação de um sistema de credenciamento de cursos de graduação para o reconhecimento regional da qualidade acadêmica dos respectivos diplomas no Mercosul e Estados Associados ${ }^{7}$.

Os dados mostraram uma estrutura curricular relativamente, similar. As diferenças residem nas cargas horárias exigidas pelas instituições para a integralização curricular (tabela 1), sendo o Paraguai o país que exige a maior carga horária total. Nesse país, atualmente, existe um movimento crítico nacional sobre a qualidade da aprendizagem nos cursos de graduação que não dispõem da motivação nem dos requisitos mínimos para cumprir adequadamente as funções no contexto de formação dos futuros profissionais ${ }^{8,9}$. Pelos argumentos de Recalde e Abente $(2018)^{8}$ e Rivarola $(2018)^{9} \quad$ se infere que não existe uma relação diretamente proporcional entre o total de carga horária obrigatória para integralização curricular e a qualidade do processo de aprendizagem e posterior atuação profissional. Cabe ressaltar que a $\mathrm{CH}$ mínima encontrada no Brasil foi de 2940h, o que está em desconformidade com a Resolução $\mathrm{n}^{\circ}$ 2, de 18 de junho de 2007, que dispõe sobre carga horária mínima e procedimentos relativos à integralização e duração dos cursos de graduação, bacharelados, na modalidade presencial, sendo que a Odontologia deve ter $\mathrm{CH}$ mínima de 4.000 horas $^{10}$.

Nos Estados Partes do Mercosul se evidencia uma tendência curricular estruturada no paradigma cirúrgico-restaurador, considerando a quantidade de carga horária disponibilizada para as competências relacionadas às Ciências Odontológicas - Clínicas Odontológicas. É evidente a supremacia de cargas horárias destinadas a esse eixo em detrimento das competências relacionadas às Ciências Humanas e Sociais e às Ciências Biológicas e da Saúde (tabela 2).

Os resultados do estudo mostram que o perfil do egresso está permeado, principalmente, de competências específicas à atuação profissional e com poucas competências relacionadas às Ciências Humanas e Sociais. Essa situação compromete a formação de recursos humanos qualificados para entender as dimensões da relação indivíduosociedade, formando profissionais incapazes de compreender os determinantes sociais, culturais, comportamentais, psicológicos, ecológicos, éticos e legais, nos níveis individual e coletivo, do processo saúde-doença ${ }^{1}$, conforme sugerido pelas DCN.

$\mathrm{Na}$ Argentina, estudantes de cursos de Odontologia preferem direcionar a futura prática profissional para uma Odontologia restauradora, altamente especializada, nas áreas de Cirurgia e Traumatologia Buco-Maxilo-Faciais, Prótese Dentária, Implantodontia, Odontopediatria, Endodontia e Ortodontia. Justificam as escolhas com base em critérios de retorno financeiro e ampliação da atuação no mercado de trabalho ${ }^{11}$.

O estudante brasileiro, ao escolher a Odontologia, pretende ao se formar, trabalhar no serviço privado, no seu consultório e com formação continuada altamente especializada ${ }^{6}$. Essas pretensões tendem a reforçar o perfil tecnicista, organicista e biomédico de atenção à saúde, caracterizado pela atenção individual, especialização precoce e intervenção terapêutica, entre outros tópicos que são evidências do modelo de atuação decorrente do conceito estático do processo saúde-doença.

Esses conceitos, de especialização precoce, têm impulsionado, também, o avanço da denominada Odontologia Estética ${ }^{7}$ focada, principalmente, nos procedimentos de qualificação da aparência sem questionar, por vezes, seus impactos desta na saúde bucal, favorecendo a sobre intervenção ou a intervenção desnecessária na procura de resultados nem sempre associados aos conceitos de saúde. Esse perfil de atuação profissional se evidencia, também, no Uruguai e no 
Paraguai. Desenvolve-se com base nas percepções dos potenciais usuários e os seus respectivos poderes aquisitivos. De forma geral, os planos de ensino em Odontologia, na região, estruturam currículos que fomentam a intervenção terapêutica de alto custo e o exercício profissional privado ${ }^{12}$.

Contudo, é imprescindível o breve estabelecimento de um processo de formação em Odontologia, de promoção de saúde, que contemple as ações de prevenção, tratamento e manutenção em consonância com a realidade epidemiológica existente no Brasil e que esta seja capaz de transformá-la ${ }^{13}$.

Em todos os países analisados, o eixo Ciências Odontológicas - Odontologia Pediátrica, tem carga horária inferior aos demais eixos propostos pelas DCN. Talvez a proposta de uma mudança neste conceito possa, por meio da redução das cargas horárias do eixo Ciências Odontológicas, subeixo, Clínicas Odontológicas (maior $\mathrm{CH}$ em todos os países membros do Mercosul), ser a chave da mudança na realidade das populações destes países. A educação para a saúde desde a infância, associada ao acesso precoce à atenção. pode ser a solução para mudar esta realidade, invertendo o que ocorre atualmente, com a maior $\mathrm{CH}$ disposta no subeixo Clínicas Odontológicas, o que caracteriza a formação de um perfil de cirurgião-dentista focado na prática curativa por meio da formação em um modelo cirúrgico-restaurador.

Nos países membros do Mercosul é comum, também, a existência dos órgãos reguladores ou de leis, decretos e portarias que estabelecem os critérios para a estruturação curricular no ensino superior, nos respectivos países. Na Argentina é a Lei no 24.521/1995, no Brasil é a Lei no 9.394/1996, no Paraguai é a Lei no 4.995/2013 e no Uruguai é o Decreto Lei $\mathrm{n}^{\mathrm{o}}$ 15.661/1984 conjuntamente com a Lei Orgânica da Universidade da República, promulgada em 1958. Nesse sentido, todos os currículos que foram analisados têm, consequentemente, o aval legal e regulatório dos países sede.

No Brasil, tanto a $\mathrm{CH}$ mínima quanto a máxima exigida para a conclusão é inferior em comparação aos outros Estados Partes, de forma ainda mais significativa quando analisados os eixos relacionados às Ciências Biológicas e da Saúde; às Ciências Odontológicas, de forma geral, assim como às competências específicas em Propedêutica Clínica e Odontologia Pediátrica, que mantêm o mesmo padrão (baixo) de $\mathrm{CH}$ para o eixo relacionado às Ciências Humanas e Sociais e o mesmo padrão (alto) de $\mathrm{CH}$ para o eixo relacionado às Ciências Odontológicas - Clínica Odontológica (tabela 2).

Pelos dados obtidos, os profissionais da Odontologia poderiam atuar nos diferentes países, pois o modelo curricular (independentemente da carga horária) é muito similar. Sabe-se que tratados internacionais podem sofrer, eventualmente, influências político-ideológicas, mas estas não devem jamais se sobrepor àqueles princípios que forjaram o Tratado de Assunção em 1991. O tratado objetivou o desenvolvimento progressivo da integração da América Latina, promovendo o desenvolvimento científico e tecnológico dos Estados Partes e a modernização das suas economias para ampliar a oferta e a qualidade dos bens de serviço disponíveis, a fim de melhorar as condições de vida de seus habitantes e, principalmente, estimular permanentemente a união, cada vez mais estreita, entre seus povos.

É importante destacar que o presente artigo não apresenta e nem analisa alguns dados relacionados à execução dos currículos, tais como a relação entre ensino, serviço e comunidade estabelecida nas DCN de 2002, reforçadas e ampliadas nas DCN 2021; aos estágios supervisionados; às atividades de extensão e ao compromisso com a produção de conhecimento que contribua para o desenvolvimento das comunidades locorregionais. Sendo assim, outros 
estudos relacionados com a temática, utilizando outras formas de coleta de dados e percursos metodológicos, são imprescindíveis para que se possa avaliar possibilidades de aproximação e trânsito livre de egressos.

\section{CONCLUSÕES}

A organização curricular dos cursos de Odontologia, nos Estados Partes do Mercosul tem similaridade. As cargas horárias totais exigidas para integralização curricular são diferentes, sendo o Paraguai o país que exige maior quantidade de horas para a formação do cirurgião-dentista e o Brasil é o país com menor carga horária exigida para a integralização curricular. Os Estados Partes exigem a maior quantidade de carga horária para o agrupamento de conteúdos essenciais (eixo) relacionado às Ciências Odontológicas - Clínica Odontológica. Em todos os Estados Partes a menor carga horária exigida está relacionada ao eixo das Ciências Humanas e Sociais.

\section{AGRADECIMENTOS}

Os autores agradecem às instituições de ensino internacionais que, quando necessário, enviaram informações adicionais às cadastradas em seus sites a fim de que contemplassem integralmente os dados necessários a este estudo, bem como à Professora Doutora Andréia Silveira Athaydes, Assessora de Relações Internacionais (International Relations Office) da ULBRA, Campus Canoas.

\section{ABSTRACT \\ Curricular structure of Mercosur countries' Dentistry undergraduate programs}

This study analyzes the curricular organization of the Dentistry Courses in Mercosur member countries, based on the essential contents' grouping structure, established by the Resolution CNE / CES n. 3 of February 19, 2002. The programs' selection was carried out from existing data of the government agencies of the different countries studied, and in the Universia database. The sample consisted of the curricula of these programs obtained in the websites of their respective institutions, comprising 141 Brazilian programs, 8 Argentinian, 2 Paraguayan, and 2 Uruguayan. The hourly loads of the disciplines of the curricular matrices of these courses were added, according to the Article 6 of the "Diretrizes Curriculares Nacionais" (DCN - Brazilian National Curricular Guidelines), which is subdivided into Biological and Health Sciences, Human and Social Sciences, and Dental Sciences. Descriptive statistics were used to analyze the data. The software used for statistical analysis was SPSS version 22.0. The analysis of the results leads to the conclusion that there is currently a similarity in the countries' curricular structure. Eventual adjustments should be made to achieve a regional professional profile, to establish in the future a strategy of "training for integration" that allows the free passage of Dentistry graduates in Mercosur Member States.

Descriptors: Curriculum. Education, Dental. Education, Higher. Evaluation Studies. Mercosur.

\section{REFERÊNCIAS}

1. Brasil. Ministério da Educação. Conselho Nacional de Educação. Câmara de Educação Superior. Resolução CNE/CES no 3, de 19 de fevereiro de 2002 [Internet]. Institui Diretrizes Curriculares Nacionais do Curso de Graduação em Odontologia. Diário Oficial da União, Brasília, DF, seção 1, p. 10, 2002 [Acesso em 2 set 2021]. Disponível em: http://portal.mec.gov.br/cne/arquivos/ pdf/CES032002.pdf.

2. Brasil. Ministério da Educação. Conselho Nacional de Educação. Câmara de Educação Superior. Resolução CNE/CES n ${ }^{\circ} 3$, de 21 de junho de 2021 [Internet]. Institui as 
Diretrizes Curriculares Nacionais do curso de graduação em Odontologia e dá outras providências. Diário Oficial da União, Brasília, DF, seção 1, ed. 115, p. 77, 2021 [Acesso em 2 set 2021]. Disponível em: https://www.in.gov.br/web/dou/-/resolucaon-3-de-21-de-junho-de-2021-327321299.

3. Andrés A. A educação superior no setor educacional do MERCOSUL. Brasília, DF, Câmara dos Deputados, Consultoria Legislativa; 2010.

4. Brandão M. Brandão M. Países firmam acordo e diplomas de graduação valem em todo o Mercosul [Internet]. Agência Brasil, Brasília, DF; 2018 [Acesso em 2 set 2021]. Disponível em: http://agenciabrasil.ebc. com.br/internacional/noticia/2018-12/paises -firmam-acordo-e-diplomas-de-graduacaovalem-em-todo-o-mercosul.

5. Mercosul. Conselho do Mercado Comum. Acordo sobre residência para nacionais dos estados partes do Mercosul. Brasília, DF, Brasil. 2002.

6. Mercosul. Conselho do Mercado Comum. Acordo de admissão de títulos e graus universitários para o exercício de atividades acadêmicas nos estados partes do Mercosul. Assunção, República do Paraguai. 1999.

7. Mercosul. Conselho do Mercado Comum. Decisão $\mathrm{n}^{\mathrm{o}} 17$ de 30 de junho de 2008. Acordo sobre a criação e a implementação de um sistema de credenciamento de cursos de graduação para o reconhecimento regional da qualidade acadêmica dos respectivos diplomados no Mercosul e Estados associados. San Miguel de Tucumán, República Argentina. 2008.

8. Recalde TSF, Abente SG. Regulamentação del ejercício professional en Medicina y Odontologia em Paraguay: uma necesidad de salud pública. Rev Bras Odontol Leg. 2018;5(3):44-51.
9. Rivarola D. La Universidad Paraguaya, hoy. Avaliação (Campinas) 2018;13(2):533-78.

10. Brasil. Ministério da Educação. Conselho Nacional de Educação. Câmara de Educação Superior. Resolução CNE/CES no 2, de 18 de junho de 2007 [Internet]. Dispõe sobre carga horária mínima e procedimentos relativos à integralização e duração dos cursos de graduação, bacharelados, na modalidade presencial. Diário Oficial da União, Brasília, DF, seção 1, 2007 [Acesso em 2 set 2021]. Disponível em: http://portal.mec.gov.br/cne/arquivos/pdf/2 007/rces002_07.pdf.

11. Sáens FI. Odontologia: la última profesión liberal. UNR Journal. 2009;2(1):437-547. [Acesso em 2 set 2021]. Disponível em: http://www.e-universitas.edu.ar/index.php/ journal/article/view/28/52.

12. Ferreira NP, Ferreira AP, Freire MCM. Mercado de trabalho na Odontologia: contextualização e perspectivas [Internet]. Rev Odontol UNESP. 2013;42(4):304-9.

13. Angar K, Busato ALS, Binotto ACC, Júnior ANS, Hernandez PAG. Os conteúdos de cirurgia e traumatologia bucomaxilofaciais na formação do cirurgião-dentista generalista. Ponta Grossa: Editora Atena; 2019.

\section{Correspondência para:}

Karine Angar

e-mail: karineangar@gmail,com

Rua Os dezoito do Forte, 2366

São Pelegrino

95020-472 Caxias do Sul/RS 